\title{
AVALIAÇÃO DO ENSINO SOBRE GESTÃO DE CADEIAS DE SUPRIMENTOS NOS CURSOS SUPERIORES DE TECNOLOGIA EM LOGÍSTICA NA GRANDE SÃO PAULO
}

\author{
EVALUATION OF TEACHING ON SUPPLY CHAIN MANAGEMENT IN HIGHER EDUCATION COURSES IN \\ TECHNOLOGY AND LOGISTICS IN GREATER SÃO PAULO \\ EVALUACIÓN DE LA ENSEÑANZA SOBRE GESTIÓN DE CADENAS DE SUMINISTROS EN LOS CURSOS \\ SUPERIORES DE TECNOLOGÍA EN LOGÍSTICA EN LA GRAN SÃO PAULO
}

ANA CRISTINA DE FARIA

Doutora

Universidade Nove de Julho - Brasil anacfaria@uol.com.br

JOSÉ ASSIS PEREIRA

Mestre

Universidade Nove de Julho - Brasil

joseassispereira@ig.com.br

IVAM RICARDO PELEIAS

Doutor

Fundação Escola de Comércio Álvares Penteado - Brasil ivamrp@fecap.br

LEANDRO CAMPI PREARO

Doutor

Universidade Municipal de São Caetano do Sul - Brasil

leandro.prearo@uscs.edu.br

RAQUEL SILVA PEREIRA

Doutora

Universidade Municipal de São Caetano do Sul - Brasil

raquelspereira@uol.com.br

Submetido em: 16/10/2012

Aprovado em: 27/11/2014

Doi: alcance.v22n2.p212-229

\section{RESUMO}

Este trabalho tem como objetivo avaliar em que medida os conteúdos sobre Gestão de Cadeias de Suprimentos ministrados nos Cursos Superiores de Tecnologia em Logística em algumas IES da Grande São Paulo atendem às demandas do mercado de trabalho. Antes do desenvolvimento de uma survey, buscou-se conhecer, por meio de pesquisa documental, as IES da região pesquisada e 60 ofertas de empregos para profissionais de Logística, oferecidas em sites de recolocação para profissionais, em que foram identificados os conhecimentos técnicos exigidos. Na survey procurou-se identificar o perfil dos sujeitos (coordenadores, docentes e alunos) e analisar suas percepções sobre a intensidade dos conteúdos oferecidos, que devem refletir os conhecimentos técnicos exigidos pelo mercado. $O$ tratamento e a análise dos dados permitiram constatar que existe convergência entre 20 conhecimentos técnicos exigidos, sendo quatro divergentes, além de um descompasso entre as percepções dos sujeitos quanto à hierarquia dos conteúdos exigidos. $O$ curso investigado nas IES alinha-se com as 
necessidades do mercado de trabalho. Recomenda-se que estas IES procurem identificar junto ao mercado os conhecimentos, as habilidades e as competências mais valorizadas no momento do planejamento desses cursos.

Palavras-chave: Curso Superior de Tecnologia. Gestão de Cadeias de Suprimentos. Logística.

\section{ABSTRACT}

The objective of this work is to evaluate whether the contents on Supply Chain Management in the Colleges of Technology (CT) in Logistics in some IHE (Institutes of Higher Education) in Greater São Paulo meet the needs of the job market. Before carrying out a survey, we sought, through document research, to find out about the IHEs located in the region of the study, and 60 job offers offered on relocation sites for Logistics professionals, in which we identified the technical knowledge required. In the survey, we aimed to identify the profile of the subjects (coordinators, teachers and students) and analyze their perceptions of the intensity of the contents offered, which should reflect the expertise required by the market. Through statistical analysis, it was found that there is convergence of 20 aspects of technical knowledge required, while only four are divergent. We also found that there is a mismatch between the perceptions of individuals regarding the hierarchy of content required by the market. The course investigated is aligned with the needs of the market, and it is recommended that IHEs seek to identify the knowledge, skills and competencies most valued by the market, when planning these courses.

Key words: Logistics. Supply Chain Management. Technology Diplomas.

\section{RESUMEN}

Este trabajo tiene como objetivo evaluar en qué medida los contenidos sobre Gestión de Cadenas de Suministros impartidos en los Cursos Superiores de Tecnología en Logística en algunas IES de la Gran São Paulo atienden a las demandas del mercado de trabajo. Antes del desarrollo de una survey se intentó conocer, por medio de un estudio documental, las IES de la región investigada y 60 ofertas de empleos para profesionales de Logística ofrecidas en sitios de recolocación para profesionales, en los que fueron identificados los conocimientos técnicos exigidos. En la survey se buscó identificar el perfil de los sujetos (coordinadores, docentes y alumnos) y analizar sus percepciones sobre la intensidad de los contenidos ofrecidos, que deben reflejar los conocimientos técnicos requeridos por el mercado. El tratamiento y el análisis de los datos permitieron constatar que existe convergencia entre 20 conocimientos técnicos exigidos, siendo cuatro divergentes, además de un desacuerdo entre las percepciones de los sujetos en relación a la jerarquía de los contenidos pedidos. El curso investigado en las IES coincide con las necesidades del mercado de trabajo. Se recomienda que estas IES procuren identificar en el mercado cuáles son los conocimientos, las habilidades y las competencias más valorizadas en el momento de la planificación de estos cursos.

Palabras clave: Curso Superior de Tecnología. Gestión de Cadenas de Suministros. Logística.

\section{INTRODUÇÃO}

A Gestão da Cadeia de Suprimentos (GCS) vem se tornando um tema de crescente importância para as organizações e diversos fatores corroboram para isso. Primeiro, as empresas estão dedicando maior atenção ao seu core competence, transferindo aos seus fornecedores o suprimento de atividades e itens que dão suporte às suas atividades principais (STOREY et al., 2006).

Em segundo lugar, estes autores consideram que a globalização dos mercados requer que as organizações possam atender às demandas locais ou em outros países, as quais acabam, na maioria das vezes, sendo realizadas por meio de outras organizações. Por fim, os autores defendem que a própria segmentação do mercado leva as organizações a utilizar-se de outros parceiros para ajudá-las na segmentação dos produtos, distribuição, vendas, entre outras atividades. Finalmente, a complexidade do gerenciamento das organizações tende a ser reduzida com a terceirização de dessas atividades para outras empresas.

Nesse contexto, a importância do profissional de Logística voltado para a GCS tem representado um diferencial competitivo na sobrevivência de empresas que buscam melhorias contínuas em seus processos produtivos, de abastecimento e de distribuição. Esta importância é atestada quando este profissional precisa 
realizar tarefas de suporte à gestão e de apoio à distribuição de serviços ou produtos em mercados cada vez mais exigentes (MYERS et al., 2004).

Na visão de Habib e Jungthirapanich (2010), o objetivo da GCS é integrar e otimizar as atividades dentro e entre organizações, visando à satisfação de todos os stakeholders. Essa satisfação ocorre em meio a toda complexidade existente nos relacionamentos na cadeia por meio da melhoria contínua das operações, de minimizações de custos, de aumentos nas margens de lucros, aumento da satisfação dos clientes e da vantagem competitiva da organização, entre outros fatores.

Diante dessa complexidade, empresas têm despertado interesses por profissionais com formação acadêmica apropriada. A busca por uma boa formação é relevante para que os profissionais que tenham conhecimento sobre Logística e GCS possam visualizar oportunidades e ameaças de mercado, bem como seus pontos fortes e fracos nas habilidades e nas competências esperadas. Por isso, os futuros tecnólogos em Logística devem estar preparados para enfrentar os desafios que esta profissão apresenta.

Para atender a essa demanda, observa-se uma evolução na oferta acadêmica por Cursos Superiores de Tecnologia (CST) em Logística, de curta duração, oferecidos por diversas Instituições de Ensino Superior (IES) que preparam o profissional para o mercado de trabalho, que está em constante atualização. Basílio (2005) aponta para a introdução de novos conteúdos ou disciplinas e, principalmente, para a reformulação dos processos de ensino e aprendizagem com estruturas curriculares flexíveis, capazes de formar egressos com 0 perfil desejado pelo mercado de trabalho.

Naturalmente, essa situação de expansão tornou o ambiente cada vez mais competitivo entre as IES, requerendo uma formação profissional qualificada do Tecnólogo de Logística. No foco deste trabalho, os CSTs em Logística são promotores da inserção de profissionais capacitados para exercerem funções voltadas à GCS. Justifica-se, dessa maneira, o desenvolvimento deste trabalho dedicado à avaliação da atual situação dos conteúdos do ensino de GCS em IES da Grande São Paulo que oferecem os CSTs em Logística.

A questão central que norteia esta pesquisa é: Os conteúdos ministrados nos CSTs em Logística em relação ao conhecimento sobre GCS estão relacionados às exigências do mercado de trabalho na Grande São Paulo? A pesquisa foi limitada à região metropolitana da Grande São Paulo em função do elevado número de IES e de empresas nacionais e estrangeiras, as quais demandam por mão de obra especializada em funções logísticas.

Para responder ao questionamento central da pesquisa, o objetivo geral deste trabalho é avaliar se os conteúdos sobre Gestão de Cadeias de Suprimentos ministrados nos cursos de Tecnologia em Logística nas IES da Grande São Paulo atendem às demandas do mercado de trabalho. Em termos específicos, objetiva-se identificar as necessidades do mercado de trabalho quanto às exigências de conhecimento de conteúdos de Logística e GCS, bem como as habilidades e as competências exigidas pelo mercado de trabalho, visando fundamentar a elaboração dos currículos desses cursos.

A pesquisa de Sodhi, Son e Tang (2008) também avaliou a percepção de alunos de MBAs americanos sobre a consonância entre os conteúdos ensinados e o exigido pelo mercado de trabalho. Estudos anteriores, tais como os de Razzaque e Sirat (2001); Gammelgaard e Larson (2001); Murphy e Poist (2007); Thai, Cahoon e Tran (2011) e Radovilsky e Hegde (2012), analisaram conteúdos que devem ser abordados no ensino de Logística e Gestão da Cadeia de Suprimentos, bem como habilidades e competências a serem adquiridas. Esta pesquisa diferencia-se das anteriores em função de analisar a percepção de coordenadores, docentes e discentes de CSTs em Logística sobre a relação entre exigências do mercado e conteúdos estudados em IES da Grande São Paulo.

\section{FUNDAMENTAÇÃO TEÓRICA}

A fundamentação teórica triangula os conceitos de Logística, de Gestão de Cadeias de Suprimentos (GCS) e de Educação Profissional, especialmente no Ensino Superior de Tecnologia em Logística ministrado no Brasil. Estes conceitos foram considerados necessários para se desenvolver o embasamento teórico a partir do qual foi realizada a pesquisa de campo.

\subsection{Logística e Gestão de Cadeias de Suprimentos (GCS)}

Revista Alcance - Eletrônica - vol. 22 - n. 2 - abr.Jjun. 2015 
Logística e GCS não são ideias novas. Desde a época da construção das pirâmides, há cerca de 4500 anos a.C., no antigo Egito, até as ações mais recentes que procuraram aliviar o sofrimento do povo do Haiti devastado por um tremor de terra em janeiro de 2010, os princípios que fundamentam o fluxo eficiente de materiais e de informações para atender às necessidades de clientes e consumidores pouco mudaram.

Diversos autores estudam estes temas. Na visão de Ballou (2007), a Logística engloba todas as atividades de transporte, movimentação e armazenagem, que facilitam o fluxo de itens físicos desde a aquisição da matéria-prima até os produtos no ponto de consumo final, assim como dos fluxos de informação que colocam os materiais/produtos em movimento, visando atingir níveis de serviços adequados aos clientes a um custo razoável. Nesse sentido, o processo logístico envolve planejamento, implementação e controle do fluxo físico de materiais, produtos finais e informações correlatas dos pontos de origem até os pontos de consumo, de modo a atender às exigências dos clientes com certa margem de lucro (CZINKOTA et al., 2001).

$\mathrm{Na}$ tentativa de proporcionar uma conceituação ainda mais ampla e completa sobre o tema, Bowersox, Closs e Cooper (2007) entendem que a Logística envolve a gestão do processamento de pedidos, os estoques, os transportes e a combinação de armazenamento, manuseio e materiais e embalagem, todos integrados por meio de uma rede de instalações. $O$ objetivo da Logística é apoiar as necessidades operacionais de compras, produção e atendimento às expectativas dos clientes. Ballou (2007) considera que, atualmente, a Logística está sendo vista como um subconjunto da GCS, estando limitada à administração das atividades interfuncionais na organização e à gestão interorganizacional no âmbito da cadeia de suprimentos.

O conceito de GCS, por sua vez, é relativamente novo no pensamento da Administração de Empresas. Para Cox et al. (2001), seu desenvolvimento deve-se à constatação, nos anos de 1970 e 1980, de que os fabricantes japoneses de automóveis administravam 0 fornecimento de insumos, além dos simples relacionamentos contratuais com os fornecedores diretos. No pensamento de Christopher (1999), a GCS procura criar vínculos e coordenação entre os processos de outras organizações existentes no canal, isto é, fornecedores e clientes e a própria organização.

Entretanto, há gestores que consideram que a troca de informação entre compradores e fornecedores tem um "lado negro" que pode eliminar os benefícios, tal como o compartilhamento de informações entre os membros da cadeia sobre questões tecnológicas, custos, preços, processos, etc., que podem "cair" nas mãos dos concorrentes (HOLWEG, 2005).

Entende-se que decisões no âmbito da Logística e da GCS implicam, geralmente, em mudanças em diferentes funções e processos organizacionais, e estão voltadas para a garantia dos objetivos maiores da empresa: oferecer o produto ou o serviço desejado demandado pelo mercado, na qualidade presumida, no lugar certo, no tempo justo e na quantidade certa, com custos competitivos e com melhoria constante nos serviços de pós-venda (COX; SANDERSON; WATSON, 2001).

Com base nisso, Closs (2000) destacou que a escassez de profissionais e gestores de cadeias de suprimentos treinados é um grande desafio nessa área, e que a Educação é necessária para 'fazer frente' a esses desafios. Para minimizar esse problema, Johnson e Pyke (2000) definiram 12 categorias a serem estudadas sobre a GCS: locação; transporte e movimentação; inventário e previsão de demanda; marketing e reestruturação de canais de distribuição; fornecimento e gestão de fornecedores; informação e ambiente de medição eletrônica; desenho de produto e introdução de novos produtos; serviços e suporte às vendas; logística reversa e questões ambientais; terceirização e alianças estratégicas e indicadores de desempenho e questões globais. Estes temas foram validados na pesquisa de Sodhi, Son e Tang (2008).

Na visão de Radovilsky e Hegde (2012), os novos conceitos de GCS a serem estudados envolvem: questões globais, como riscos e rupturas/rompimentos na cadeia de suprimentos; segurança do produto; sustentabilidade e cadeia de suprimentos verde; orientação para o serviço; cultura e linguagem; questões legais e contratuais; gestão enxuta e desenvolvimento de tecnologia de informação.

Lancioni, Forman e Smith (2001), por sua vez, destacam que a Logística, como área formal de estudo, ganhou popularidade em colégios e universidades nos Estados Unidos desde a década de 1970, com a formação de duas organizações de gestão de profissionais: The National Council of Phisical Distribution Management (NCPDM) e Society of Logistics Engineers (SOLE). No Brasil, a partir da década de 1960, foram desenvolvidos os Cursos de Tecnologia, e o interesse específico pela Logística despertou o interesse das IES a partir da década de 1990. No próximo tópico, tratar-se-á sobre o Ensino de Tecnologia no Brasil e, na sequência, especificamente sobre o CST em Logística. 


\subsection{Ensino de Tecnologia no Brasil}

Neste tópico, realizar-se-á uma síntese descritiva da Educação Profissional no Brasil, focalizando nos Cursos Superiores de Tecnologia (CST) em Logística.

\subsubsection{A Educação Profissional no Brasil}

A Educação brasileira, ao longo da história, tem sido tratada de forma preconceituosa e influenciada por uma herança colonial escravista (BASİLIO, 2005). De acordo com este autor, a Educação profissional, durante dois séculos de história nacional, foi direcionada para pessoas que faziam parte das camadas sociais economicamente menos favorecidas (BASİLIO, 2005).

Para Takahashi (2005), a força de trabalho brasileira contou, por muito tempo, com trabalhadores carentes de qualificação. Esta linha de pensamento é tratada também dentro do Parecer CNE/CEB 16/1995, no qual a formação profissional sempre foi, desde a sua origem, reservada às classes menos favorecidas, estabelecendo-se uma nítida distinção entre aqueles que detinham o saber (ensino secundário, normal e superior) e os que executavam tarefas manuais (ensino profissional).

A partir da década de 1950, com o processo de industrialização brasileira e a organização da produção, aliada às crescentes inovações tecnológicas nos processos produtivos, as empresas passaram a requerer, cada vez mais, dos trabalhadores das organizações, profissionais com formação escolar básica, acompanhada de contínua qualificação profissional. Nesse contexto surgiram, respaldados pela Lei $n^{0} 4.024 / 61$, os Cursos Superiores de Tecnologias (CSTs), por meio da primeira LDB que, em seu art. 104, contemplava "a organização de cursos ou escolas experimentais, com currículos, métodos e períodos escolares próprios" (LIMA FILHO, 2010).

O Decreto-lei $n^{0} 547$, no ano de 1969, autorizou o funcionamento dos cursos superiores de curta duração nas escolas técnicas federais, apoiadas pelas necessidades do mercado e pelo crescente desenvolvimento tecnológico, por meio dos cursos de Engenharia operacional com duração de três anos, aprovada pelo Parecer CFE $n^{0} 60 / 63$, que visava à formação de um perfil profissional focado, principalmente, na atividade de supervisão de setores especializados da indústria. Nessa época, em São Paulo, os CSTs foram criados e implantados, de forma incipiente, pelo Centro Estadual de Educação Tecnológica Paula Souza (BASILIO, 2005).

A partir do ano de 1972, o Governo Federal expandiu seu projeto em todo o país, criando em 1976 o Centro de Educação Tecnológica da Bahia (Centec/BA), exclusivamente para a formação de tecnólogos e, em 1978, os centros federais de educação tecnológica do Paraná, Minas Gerais e Rio de Janeiro. Com a promulgação da Lei $n^{0}$ 8.948, a partir de 1994 aos dias atuais, as antigas escolas técnicas e algumas agrotécnicas federais foram transformadas em Centros Federais de Educação Tecnológica (CEFETs) e também passaram a oferecer Cursos Superiores de Tecnologia.

No âmbito das universidades públicas surgiram, nos anos 1970 e 1980, os cursos de formação de tecnólogos com menor duração, direcionados às necessidades imediatas do setor produtivo (MOURA, 2005). Esses cursos, em seu formato inicial, não sobreviveram no sistema das universidades públicas brasileiras. Corroborando com esse fato, Basílio (2005) observou que alguns desses cursos foram extintos no setor público, tal como o de engenharia operacional, passando, a partir dessa época, a oferta ser feita por meio de instituições privadas.

Apesar de a Lei 8.948 já ter instituído o Sistema Nacional de Educação Tecnológica em 1994, foi a partir da Lei 9.394/96 - Lei de Diretrizes e Bases Nacionais (LDBN) e do Decreto Federal 2.208/97, que o Ensino Tecnológico ganhou nova dimensão, abrangendo a Educação profissional em três níveis de ensino: básico, técnico e tecnológico. Esse último corresponde à graduação superior, destinado aos egressos do ensino médio ou técnico.

Bailey, Badaway e Gumport (2003) relatam que, em alguns países, como os Estados Unidos, este sistema de formação profissional é conhecido como Community College. Este tipo de faculdade, com conclusão em dois anos, é destinado às populações de estudante como as minorias, especialmente negros e hispânicos, que representam uma parcela maior e, em seguida, as mulheres. Argumentam os autores aos gestores da comunidade universitária e professores que muitos alunos não chegam procurando graus; ao contrário, estão

Revista Alcance - Eletrônica - vol. 22 - n. 2 - abr.jjun. 2015 
buscando habilidades específicas que podem aprender em cursos e programas de certificação mais curtos, tais como os CSTs.

\subsubsection{Os Cursos Superiores de Tecnologia - CST em Logística no Brasil}

A partir da introdução da LDBN e do Decreto Federal 2.208/97, o ensino tecnológico ganhou nova dimensão e reiniciou sua trajetória no Ensino Superior brasileiro; pois, segundo Takahashi (2010), passou por uma reformulação a fim de atender às demandas atuais do setor produtivo e ampliar o acesso ao ensino superior. Os Cursos Superiores de Tecnologia (CST) surgiram na década de 1970, quando a força de trabalho brasileira apresentava carência de trabalhadores qualificados (CORDÃO, 2002).

De acordo com o Instituto Nacional de Estudos e Pesquisas Educacionais - INEP (2010), na última década houve um crescimento significativo de matriculados nos CSTs nas IES que oferecem este curso. As IES privadas contavam, em 2001, com 43.926 alunos matriculados nos cursos de Tecnologias, enquanto que, em 2009, houve um crescimento para 578.789 alunos, uma evolução de 1.217,65\%. Enquanto que nas IES públicas, um crescimento de 293,84\%. De acordo com o Parecer CNE/CES n . 436/2001, aprovado pela Câmara de Educação Superior do Conselho Nacional de Educação, os CSTs são definidos como de Graduação, mas com características especiais e distintas dos cursos tradicionais.

Durante a década de 1990, o Brasil passou por um período de abertura em sua economia, com influência direta nos processos de globalização, resultando na concorrência entre produtos importados e nacionais (GANGA et al., 2003). Nesse cenário, surge a oportunidade de explorar no Brasil a formação de profissionais na área de Logística. Com a projeção alcançada nos últimos anos, a Logística tornou-se estratégica para as empresas, além de promissora e fortemente requisitada pelo mercado, conforme comentam Figueiredo e Arkader (1999) e Georges e Seydell (2008), gerando uma maior oferta de cursos voltados para este assunto nas Universidades.

Dentro desse panorama, compreendendo as necessidades do mercado, o Ministério da Educação e Cultura - MEC, em 2006, visando organizar e orientar a oferta de Cursos Superiores de Tecnologia, lançou 0 Catálogo Nacional de Cursos Superiores de Tecnologia, em que define um perfil de competências esperadas ao profissional de Tecnologia em Logística. Este catálogo contempla conhecimentos especializados sobre aquisição, recebimento, armazenagem, distribuição e transporte.

Considera-se que este profissional atuará planejando e coordenando a movimentação física e de informações, desenvolvendo e gerenciando sistemas de gestão de materiais e de estoques, estabelecendo processos de compras, identificando fornecedores e controlando recursos financeiros. As responsabilidades para o exercício de suas atividades exigem visão sistêmica e estratégica, capacidade de comando, liderança e conhecimentos de estratégias e tecnologias de segurança (MEC, 2006, p.37).

Nota-se que conciliar teoria e prática no ensino de Logística, de modo a transmitir e assimilar seus conteúdos, tornou-se uma tarefa desafiadora para professores e alunos, o que gerou maior necessidade do oferecimento deste curso nas Universidades. O Curso Superior de Tecnologia em Logística, até 2012, no Brasil, não passou pelo Exame Nacional de Desempenho de Estudantes (ENADE), coordenado pelo INEP.

De acordo com o INEP (2010), a situação atual do Curso de Tecnologia em Logística, no Brasil, apresenta um crescimento expressivo de $7.100 \%$ nas IES particulares no ano de 2009 comparado com 2001; em que apenas três IES ofereciam este tipo de curso. Já as IES públicas passaram a oferecer esse tipo de curso, com três IES a partir do ano de 2004, apresentando em 2009 um crescimento de 333,33\%, com treze IES ofertantes.

Acompanhando este cenário, houve crescimento acelerado de matrículas nas IES privadas na modalidade presencial, que apresentava apenas 362 alunos durante o ano de 2001, com uma taxa de crescimento extraordinário de $11.004,70 \%$, com 40.199 alunos, enquanto nas IES públicas houve um crescimento de 204,96\%, comparando o período de 2004/2009 (INEP, 2010). Percebe-se que, no crescimento econômico ao longo da primeira década deste século no Brasil, os cursos de tecnologia em Logística encaixamse no atual cenário de negócios.

\section{ASPECTOS METODOLÓGICOS}

Ana Cristina de Faria, José Assis Pereira, Ivam Ricardo Peleias, Leandro Campi Prearo e Raquel Silva Pereira 
Esta é uma pesquisa exploratória que, conforme Gil (2010, p.27), objetiva proporcionar familiaridade com o problema, para torná-lo mais explícito ou construir hipóteses. Seu planejamento é flexível e, na maioria dos casos, requer levantamento bibliográfico, aplicação de questionários e entrevistas com pessoas envolvidas com o problema pesquisado e análise de exemplos que estimulem a compreensão. Buscou-se desenvolver o estudo conforme seus objetivos, seguindo uma pesquisa exploratória descritiva, de natureza quantitativa. As características deste tipo de abordagem permitem o uso de quantificação na coleta de informações e no seu tratamento estatístico (RICHARDSON, 2007)

Foram verificadas quais IES localizadas na Região Metropolitana da Grande São Paulo oferecem CSTs em Logística, usando como fonte de informações o Cadastro Nacional de cursos do MEC (2010), em que foram encontradas $41 \mathrm{IES}$, sendo todas convidadas a participar da pesquisa, mas apenas 4 concordaram em participar.

O tipo de amostragem utilizado é por conveniência e intencional, em função da acessibilidade às informações, definida por Cooper e Schindler (2003, p. 169) como "uma amostragem não-probabilística que atenda a certos critérios". Foi possível realizar a pesquisa em quatro das 41 IES que oferecem este tipo de curso na região metropolitana de São Paulo, representando 9,76\% desta população. Considera-se que a amostra escolhida atende às necessidades dos pesquisadores. Os resultados estão adstritos às 4 IES selecionadas para a pesquisa, não sendo possivel extrapolá-los para generalizar a situação de todas as 41 IES.

Posteriormente, por meio de uma pesquisa documental em sites de recolocação profissional, tais como Catho (2011), Michael Page (2011) e Manager (2011), verificaram-se, no acesso a 60 anúncios voltados para a área de Logística no início de Fevereiro de 2011, quais os conhecimentos técnicos exigidos aos profissionais de Logística, em nível de tecnologia. Razzaque e Sirat (2001) sugerem que o foco em competências e conteúdos necessários que fazem um bom técnico em logística tem sido bastante escasso. Da mesma forma, Gammelgaard e Larson (2001) acrescentam que são escassos trabalhos científicos sobre os conhecimentos técnicos exigidos pelo mercado de trabalho.

A fim de facilitar a coleta e o tratamento de dados, foram elaborados três questionários estruturados para realização de uma survey, que ocorreu entre os meses de maio e junho de 2011. De acordo com Babbie (2001, p. 96), "surveys são frequentemente realizadas para permitir enunciados descritivos sobre alguma população". Foi usado um instrumento de coleta de dados em que os respondentes (5 coordenadores, 68 docentes focados no ensino dos conteúdos específicos de Logística e GCS e 212 discentes) deveriam preenchêlo, visando elucidar informações específicas.

$O$ instrumento de pesquisa destinado aos coordenadores continha 31 quesitos; 0 dos docentes continha 30 quesitos e o dos discentes apresentou 29 quesitos a serem avaliados, que incluíam, basicamente, os conteúdos destacados pelos anúncios obtidos na pesquisa documental sobre as exigências do mercado de trabalho na área pesquisada. A versão preliminar dos instrumentos de pesquisa passou por um pré-teste, em que se buscou identificar como os respondentes usavam as escalas de respostas possiveis para cada variável.

Nos três questionários desenvolvidos, cada uma das variáveis operacionais propostas possuía escala intervalar para poder ser utilizada posteriormente nas análises estatísticas planejadas. Malhotra (2006, p.247) assevera que a escala intervalar é aquela na qual são usados números para pontuar/classificar objetos, de tal modo que distâncias numericamente iguais na escala representem distâncias iguais na característica que está sendo medida.

Criou-se uma escala itemizada, de mensuração, que apresenta números ou breves descrições associadas a cada categoria (MALHOTRA, 2006, p. 265). As categorias são ordenadas em termos de sua posição na escala. Foi adotada a escala itemizada do tipo Likert de diferencial semântico bipolar, com onze pontos. Na escala bipolar, de acordo com Matsukuma e Hernandez (2006), apenas os extremos da escala são descritos. Os entrevistados escolhem sua resposta, sabendo que, quanto mais próximo de um dos extremos, mais o objeto que está sendo avaliado encontra-se próximo àquele extremo.

Para responder cada questão, basta o respondente atribuir a cada afirmação um escore numérico de 0 (zero) a 10 (dez). Para realizar a pesquisa, foi preciso obter e consolidar três questionários diferentes direcionados para alunos, professores e coordenadores das IES pesquisadas. Os dados obtidos foram tratados por estatística descritiva e testes não paramétricos, que serão desenvolvidos no tópico a seguir. 


\section{APRESENTAÇÃO E DISCUSSÃO DOS RESULTADOS}

Neste tópico, inicialmente, apresentam-se os resultados obtidos nos sites de recolocação e, em seguida, os obtidos na survey com coordenadores, professores e discentes do Curso Superior de Tecnologia em Logística das quatro IES pesquisadas. Ao final, realiza-se um comparativo entre as exigências do mercado de trabalho e a percepção dos pesquisados.

\subsection{Resultados da Pesquisa em Sites de Recolocação}

A pesquisa documental possibilitou classificar os conhecimentos técnicos exigidos pelo mercado de trabalho. Os conhecimentos técnicos exigidos pelos anúncios de vagas apresentam-se condizentes com a pesquisa de Van Hoek (2001) em diversos periódicos, sobre quais os assuntos mais abordados nestes e com a fundamentação teórica da GCS de autores como Simchi-Levi et al. (2010).

Nos 60 anúncios pesquisados nos sites citados na Metodologia, foram identificados 24 itens mais exigidos, com um total de 245 incidências nos diversos cargos relacionados à Logística. Constatou-se que 10 conteúdos correspondem a $71,84 \%$ da incidência dos conhecimentos relativos à GCS: Indicadores de desempenho; Distribuição, Gestão de estoques; Planejamento, programação e controle da produção (PPCP); Gestão de transportes; Gestão de compras; Armazenagem e movimentação de cargas; Custo/Finanças; Gestão de armazéns e Supply chain.

Estes resultados estão em consonância com a pesquisa de Sodhi, Son e Tang (2008) que foi realizada em 55 MBAs nos Estados Unidos da América, em que se constatou que os temas que as escolas de negócios, em nível de Lato Sensu, enfatizam mais que o mercado de trabalho são: reestruturação da cadeia de suprimentos; Tecnologia de Informação; Logística; questões globais (coordenação e colaboração); Desenho de produto, postponement e variedade de produtos; gestão global; comércio eletrônico; reposição e gestão do canal de distribuição. Todos os conteúdos exigidos pelo mercado de trabalho estão inseridos no contexto da GCS e em consonância com o perfil do egresso recomendado pelo catálogo do MEC.

\subsection{Pesquisa com Coordenadores}

De acordo com as respostas de cinco coordenadores atuantes nas quatro IES pesquisadas, pois uma delas possuía dois coordenadores, foi possível traçar um perfil destes:

Tabela 1: Perfil dos coordenadores do CST em Logística

\begin{tabular}{l|l|c}
\hline \multicolumn{1}{c|}{ Assertiva } & Respondentes \\
\hline \hline \multirow{2}{*}{$\begin{array}{l}\text { Tempo na função de coordenador de Tecnologia em } \\
\text { Logística }\end{array}$} & Menos de um ano & 2 \\
\cline { 2 - 3 } & Entre um e cinco anos & 2 \\
\cline { 2 - 3 } & Mais de cinco anos & 1 \\
\hline \multirow{2}{*}{$\begin{array}{l}\text { Atividades fora da coordenação } \\
\text { Formação e titulação }\end{array}$} & Exerce outra atividade fora da logística & 5 \\
\cline { 2 - 3 } & Leciona na área da logística & 0 \\
\cline { 2 - 3 } & Só coordena & 0 \\
\hline & Só Graduado & 2 \\
\cline { 2 - 3 } & Especialista & 3 \\
\cline { 2 - 3 } & Mestre & 0 \\
\cline { 2 - 3 } & Doutor & 1 \\
\hline \multirow{2}{*}{ Participação na elaboração do projeto pedagógico } & Não & 4 \\
\cline { 2 - 3 } & Sim & 0 \\
\hline
\end{tabular}

Ana Cristina de Faria, José Assis Pereira, Ivam Ricardo Peleias, Leandro Campi Prearo e Raquel Silva Pereira 
Conhece os requisitos demandados pelo mercado de trabalho

Atualiza constantemente os conteúdos do curso

\begin{tabular}{l|c}
\hline Conheço parcialmente & 0 \\
\hline Conheço totalmente & 5 \\
\hline Não conheço & 0 \\
\hline Conheço parcialmente & 1 \\
\hline Conheço totalmente & 4 \\
\hline Não & 0 \\
\hline Sim & 5 \\
\hline
\end{tabular}

Fonte: Dados da pesquisa (2011).

Constatou-se que três coordenadores de CSTs em Logística estão no cargo há mais de um ano $(60 \%)$, enquanto dois estão há menos de 1 ano (40\%), indicando uma rotatividade na função ou a recente criação dos cursos, o que dificulta o conhecimento sobre a realidade do curso e, ainda, a melhoria e a implementação de ações no médio e longo prazo. Todos os coordenadores lecionam no curso, o que os aproxima dos demais docentes, dos discentes e do que ocorre no mercado de trabalho. Com relação à titulação dos coordenadores, três possuem mestrado (60\%) e dois são especialistas (40\%).

Na participação dos coordenadores na concepção do CST em Logística, apenas um afirmou que não participou na elaboração do projeto pedagógico; entretanto todos afirmaram conhecer plenamente 0 projeto pedagógico. Apenas um coordenador afirmou conhecer parcialmente os requisitos demandados pelo mercado de trabalho e o restante afirmou conhecer plenamente estes requisitos, um indicativo de que estes elementos estão fortemente focados nas necessidades de conteúdos nos seus cursos. Há unanimidade de todos os respondentes, que atualizam constantemente os conteúdos das disciplinas do CST em Logística. A Tabela 2 apresenta uma análise mais aprofundada sobre isso:

Tabela 2: Comparativo entre a média dos escores dos coordenadores e quantidade de anúncios com conhecimentos exigidos pelo mercado de trabalho

\begin{tabular}{c|l|c|c|c}
\hline \hline Item & \multicolumn{1}{|c|}{ Conteúdos exigidos pelo mercado de trabalho } & Média & Mediana & $\begin{array}{c}N^{0} \text { de } \\
\text { anúncios }\end{array}$ \\
\hline 5.4 & Planejamento, programação e controle da produção (PPCP) & 9,8 & 10,0 & 21 \\
\hline 5.10 & Supply chain & 9,4 & 10,0 & 11 \\
\hline 5.2 & Distribuição & 9,0 & 9,0 & 24 \\
\hline 5.8 & Custos/finanças & 9,0 & 9,0 & 12 \\
\hline 5.7 & Armazenagem e movimentação de cargas & 8,8 & 9,0 & 14 \\
\hline 5.16 & Logística internacional & 8,8 & 9,0 & 6 \\
\hline 5.17 & Relacionamento com clientes & 8,8 & 9,0 & 6 \\
\hline 5.18 & Canais de distribuição & 8,8 & 9,0 & 4 \\
\hline 5.24 & Planejamento estratégico & 8,8 & 9,0 & 2 \\
\hline 5.3 & Gestão de estoques & 8,6 & 8,0 & 22 \\
\hline 5.11 & Gestão de pessoas & 8,6 & 9,0 & 8 \\
\hline 5.5 & Gestão de transportes & 8,4 & 8,0 & 19 \\
\hline 5.9 & Gestão de armazéns & 8,2 & 8,0 & 11 \\
\hline 5.19 & Sistemas/fluxo de informações & 8,2 & 9,0 & 4 \\
\hline 5.20 & Gerenciamento de projetos & 8,0 & 8,0 & 3 \\
\hline 5.21 & Logística reversa & 8,0 & 8,0 & 2 \\
\hline
\end{tabular}

Revista Alcance - Eletrônica - vol. 22 - n. 2 - abr.jjun. 2015 
Disponível em: www.univali.br/periodicos

\begin{tabular}{cl|c|c|c}
5.22 & Roteirização & 8,0 & 9,0 & 2 \\
\hline 5.23 & Gestão da qualidade & 8,0 & 9,0 & 2 \\
\hline 5.14 & Gestão de operações & 7,8 & 8,0 & 8 \\
\hline 5.12 & Gestão de operadores logísticos & 7,6 & 7,0 & 8 \\
\hline 5.13 & Gestão de contratos & 7,4 & 7,0 & 8 \\
\hline $\mathbf{5 . 6}$ & Gestão de compras & $\mathbf{7 , 0}$ & $\mathbf{6 , 0}$ & $\mathbf{1 8}$ \\
\hline $\mathbf{5 . 1}$ & Indicadores de desempenho & $\mathbf{6 , 8}$ & $\mathbf{6 , 0}$ & $\mathbf{2 4}$ \\
\hline 5.15 & Follow up de pedidos & 6,8 & 7,0 & 6 \\
\hline \hline
\end{tabular}

Fonte: Dados da pesquisa (2011).

Na Tabela 2, observa-se que dois conteúdos, Gestão de Compras e Indicadores de Desempenho, obtiveram respectivamente escore médio de 7,0 e 6,8 e que aparecem com grande procura nos requisitos demandados pelo mercado de trabalho. Tais requisitos mostram que, nos anúncios obtidos na pesquisa, os dois conteúdos são requisitados em grande parte destes anúncios. Dessa maneira, considerando a média da intensidade dos escores dos coordenadores, tais conteúdos deveriam passar por uma atualização para atender os requisitos do mercado de trabalho.

Buscou-se avaliar as opiniões dos coordenadores sobre a intensidade dos conteúdos e conhecimentos passados aos alunos nas disciplinas aplicadas em sala de aula. Levando-se em consideração a escala semântica bipolar, 18 assertivas sobre os conteúdos são consideradas próximas à intensidade muitíssimo forte (nota 8 ou mais), enquanto apenas 6 destes conteúdos passados aos alunos estão fora desta intensidade. De modo geral, constata-se que os coordenadores acreditam que os conteúdos ensinados estão em sintonia com as necessidades do mercado de trabalho, principalmente no que diz respeito à PPCP, à Distribuição, à Gestão de Estoques, à Gestão de Transportes, aos Custos/finanças e à Armazenagem e à movimentação de cargas.

\subsection{Pesquisa com Docentes}

Constatou-se na pesquisa que $10,53 \%$ dos 68 docentes trabalham há menos de um ano nas IES pesquisadas, enquanto $57,89 \%$ afirmaram estar entre um e cinco anos e $31,58 \%$ dos respondentes mais de cinco anos de permanência nas IES. Este resultado aponta uma estabilidade no corpo docente, fazendo com que os mesmos tenham afinidade com o curso. Apenas $42,11 \%$ dos professores exercem atividades extradocentes alinhadas com as disciplinas que lecionam e 31,58\% exercem outra atividade fora da docência, sem nenhuma relação com as disciplinas que lecionam e, finalmente, $26,32 \%$ admitem que não exercem nenhuma atividade fora da área acadêmica.

Observou-se que há relevância de docentes que atuam profissionalmente na área da Logística, os quais alinham as práticas do dia a dia com os conteúdos ensinados, fortalecendo o saber fazer com as teorias discutidas em sala de aula. Entretanto, este resultado mostra que as IES devem se preocupar com o corpo docente, elevando a participação de profissionais que atuem na área da logística, dando ênfase no saber fazer. Quanto à titulação dos docentes, $10,53 \%$ são doutores; $26,32 \%$, mestres e a grande maioria, $63,16 \%$, é de especialista. Nos respondentes não havia professores somente graduados. Assim, é demonstrado que as IES estão em consonância com a LDBN, que define a composição do corpo docente com titulação acadêmica de mestrado ou doutorado na proporção de um terço em relação ao total de docentes.

Buscou-se conhecer o envolvimento do docente no desenvolvimento do curso de Tecnologia em Logística das IES. Constatou que, em relação à participação do professor na elaboração do projeto pedagógico do curso, $89,47 \%$ responderam que não tiveram nenhuma participação, enquanto 10,53\% tiveram participação. Estes resultados apontam uma pequena participação de professores no projeto pedagógico, apesar de que $89 \%$

dos docentes estão nas instituições há mais de um ano, sendo natural esperar que deveriam estar envolvidos com este projeto. 
Evidencia-se que $52,63 \%$ dos respondentes conhecem parcialmente o projeto pedagógico do curso; $36,84 \%$ conhecem totalmente e somente 10,53\% disseram não conhecer. Quanto aos requisitos demandados pelo mercado de trabalho, observou-se que $73,68 \%$ dos professores declararam conhecer totalmente as demandas dos requisitos desejados, enquanto $21,05 \%$ relataram conhecer parcialmente estes requisitos e $5,26 \%$ declararam não conhecer.

\subsection{Pesquisa com Discentes}

Quanto à situação atual de empregabilidade dos alunos, 35,85\% dos 212 respondentes afirmaram não estar trabalhando, já que parte deles era de séries iniciais; enquanto $36,79 \%$ responderam que trabalham na área do curso e o restante, $27,36 \%$, trabalha fora da área do curso. Na segunda questão, a afirmação sobre a escolha do motivo do curso de Tecnologia em Logística, a grande maioria assinalou que a escolha do curso deveu-se à possibilidade de maiores chances na conquista de empregos. Esse resultado corrobora com os objetivos do Decreto n 2.208 de 17/04/97, que é a inserção de jovens e adultos no mundo do trabalho.

Assevera-se nesse questionamento que existe um conhecimento sobre o atual estágio da importância da Logística nas empresas, o que possibilita grandes oportunidades de empregos. Na soma das respostas dos itens, $120(56,60 \%)$ acreditam nesta possibilidade; $34(16,04 \%)$ escolheram o curso por já trabalhar na área e 58 $(27,36 \%)$ dos respondentes atribuíram a escolha por ter algum conhecimento da área e gosto pelo curso. Posteriormente, buscou-se avaliar as opiniões dos discentes sobre se o conteúdo ensinado tem relação com seu trabalho, se contempla o seu aproveitamento no dia a dia nas tarefas executadas por eles em seu trabalho e, finalmente, se a organização e os conteúdos estão preparando-os para o desempenho profissional.

Tabela 3: Opinião sobre o CST em Logística

\begin{tabular}{|c|c|c|c|c|}
\hline & & \multicolumn{3}{|c|}{ Assertivas } \\
\hline \multicolumn{2}{|c|}{ Intensidade } & $\begin{array}{l}\text { O conteúdo ensinado tem } \\
\text { relação com o trabalho } \\
\text { discente }\end{array}$ & $\begin{array}{l}\text { Aproveitamento no dia a dia } \\
\text { nas tarefas executadas }\end{array}$ & $\begin{array}{l}\text { A organização e os conteúdos } \\
\text { estão preparando-os para } \\
\text { desempenho profissional }\end{array}$ \\
\hline \multirow{3}{*}{ Muitíssimo fraco } & 0 & \multirow{3}{*}{$4,7 \%$} & \multirow{3}{*}{$4,2 \%$} & \multirow{3}{*}{$1,4 \%$} \\
\hline & 1 & & & \\
\hline & 2 & & & \\
\hline \multirow{6}{*}{$\downarrow$} & 3 & \multirow{6}{*}{$73,6 \%$} & \multirow{6}{*}{$80,7 \%$} & \multirow{6}{*}{$72,7 \%$} \\
\hline & 4 & & & \\
\hline & 5 & & & \\
\hline & 6 & & & \\
\hline & 7 & & & \\
\hline & 8 & & & \\
\hline \multirow{2}{*}{ Muitíssimo forte } & 9 & \multirow{2}{*}{$21,7 \%$} & \multirow{2}{*}{$15,1 \%$} & \multirow{2}{*}{$25,9 \% \%$} \\
\hline & 10 & & & \\
\hline \multicolumn{2}{|l|}{ Total } & 100 & 100 & 100 \\
\hline
\end{tabular}

Fonte: Dados da Pesquisa (2011).

Considerada a escala semântica bipolar, na Tabela 3, observa-se que, na intensidade 'muitíssimo fraco', apenas $4,7 \%$ dos respondentes entendem que o conteúdo ensinado não tem relação com o seu trabalho, enquanto no outro extremo (Muitíssimo forte), 21,7\% acharam que há relação no que é ensinado em sala de aula. Quanto à opinião dos discentes, enfatizando se o conteúdo contempla o seu aproveitamento no dia a dia nas tarefas executadas no seu trabalho, somente $4,2 \%$ responderam no primeiro polo (Muitíssimo fraco), enquanto no outro extremo, apenas $15,1 \%$ disseram que o conteúdo aplicado é suficiente na aplicação no seu dia a dia no trabalho. 
Em relação à assertiva se a organização e os conteúdos estão preparando-os para o desempenho profissional, os dados revelam que apenas $1,4 \%$ dos alunos neste quesito não está satisfeitos, achando que não estão sendo preparados para o desempenho do exercício profissional de Tecnólogo em Logística. Na outra ponta, $25,9 \%$ dos respondentes estão satisfeitos com a preparação do curso para o exercício das atividades de logística.

A maioria dos respondentes está situada na faixa intermediária, com intensidade próxima à forte, 0 que na visão dos alunos representa que as IES estão cumprindo seu papel, preparando-os para o mercado de trabalho, de acordo com o Parecer $n^{0}$ 29/2002, que estabelece que a organização curricular deve ser atualizada conforme as demandas sociais e do mercado de trabalho; por isso, deverá focar as competências profissionais do tecnólogo e o perfil de conclusão pretendido.

\subsection{Comparativo entre exigências do mercado e percepções dos pesquisados}

A análise dos resultados foi realizada com auxílio do software Statistical Package for the Social Sciences - SPSS - Versão 17.0. Apresenta-se na Tabela 4 a comparação dos indicadores do grupo de discentes e a visão dos docentes:

Tabela 4: Comparação entre a opinião dos docentes e discentes

\begin{tabular}{l|c|c|c|c|c|c}
\hline \multirow{2}{*}{\multicolumn{1}{c|}{ Conteúdos exigidos pelo mercado de trabalho }} & \multicolumn{2}{|c|}{ Discentes } & \multicolumn{2}{c|}{ Docentes } & \multirow{2}{*}{ Z } & \multirow{2}{*}{ Sig. } \\
\cline { 2 - 6 } & Média & Mediana & Média & Mediana & & \\
\hline \hline Indicadores de desempenho & 6,7 & 7,0 & 6,1 & 7,0 & $-0,772$ & 0,782 \\
\hline Distribuição & 7,0 & 7,0 & 7,1 & 7,0 & $-0,114$ & 0,548 \\
\hline Gestão de estoques & 7,2 & 8,0 & 7,3 & 8,0 & $-0,062$ & 0,554 \\
\hline Planejamento, programação e controle da produção (PPCP) & 7,0 & 7,0 & 6,1 & 7,0 & $-1,196$ & 0,388 \\
\hline Gestão de transportes & 7,1 & 7,0 & 5,8 & 6,0 & $-1,442$ & 0,314 \\
\hline Gestão de compras & 6,4 & 7,0 & 6,0 & 7,0 & $-0,491$ & 0,702 \\
\hline Armazenagem e movimentação de cargas & 7,4 & $\mathbf{8 , 0}$ & $\mathbf{5 , 9}$ & $\mathbf{7 , 0}$ & $\mathbf{- 1 , 7 8 4}$ & $\mathbf{0 , 0 8 5}$ \\
\hline Custos/finanças & 7,1 & 7,0 & $\mathbf{5 , 9}$ & $\mathbf{6 , 0}$ & $\mathbf{- 1 , 6 9 9}$ & $\mathbf{0 , 0 5 5}$ \\
\hline Gestão de armazéns & 7,0 & 7,0 & 5,6 & 6,0 & $-1,658$ & 0,167 \\
\hline Supply chain & 7,0 & 7,0 & 7,2 & 8,0 & $-0,154$ & 0,263 \\
\hline Gestão de pessoas & $\mathbf{6 , 7}$ & $\mathbf{7 , 0}$ & $\mathbf{5 , 8}$ & $\mathbf{6 , 0}$ & $\mathbf{- 4 , 0 1 1}$ & $\mathbf{0 , 0 0 0}$ \\
\hline Gestão de operadores logísticos & 6,3 & 7,0 & 6,1 & 7,0 & $-1,076$ & 0,430 \\
\hline Gestão de contratos & $\mathbf{6 , 0}$ & $\mathbf{7 , 0}$ & $\mathbf{5 , 4}$ & $\mathbf{5 , 0}$ & $\mathbf{- 3 , 0 3 7}$ & $\mathbf{0 , 0 0 4}$ \\
\hline Gestão de operações & 6,2 & 7,0 & 4,7 & 5,0 & $-0,347$ & 0,815 \\
\hline Follow up de pedidos & 6,4 & 7,0 & 5,5 & 6,0 & $-0,819$ & 0,356 \\
\hline Logística internacional & 6,9 & 7,0 & 6,2 & 7,0 & $-1,667$ & 0,101 \\
\hline Relacionamento com clientes & 6,6 & 7,0 & 6,4 & 7,0 & $-1,051$ & 0,412 \\
\hline Canais de distribuição & 6,4 & 7,0 & 6,1 & 7,0 & $-0,848$ & 0,754 \\
\hline Sistemas/fluxo de informações & 6,7 & 7,0 & 5,4 & 6,0 & $-0,197$ & 0,928 \\
\hline Gerenciamento de projetos & 6,1 & 7,0 & 5,8 & 7,0 & $-0,437$ & 0,668 \\
\hline Logística reversa & 6,8 & 7,0 & 6,5 & 7,0 & $-1,632$ & 0,109 \\
\hline Roteirização & & & 6,7 & 7,0 & $-0,283$ & 0,952 \\
\hline
\end{tabular}


Gestão da qualidade

Planejamento estratégico

\begin{tabular}{l|l|l|l|l|l}
6,8 & 7,5 & 6,5 & 7,0 & $-0,513$ & 0,601 \\
\hline 6,8 & 7,0 & 6,7 & 7,0 & $-0,222$ & 0,997 \\
\hline
\end{tabular}

Fonte: Dados da pesquisa (2011).

A análise foi iniciada com o estudo exploratório dos dados, para avaliar as possibilidades de tratamento com métodos estatísticos. Para isso, foi aplicado o teste de Kolmogorov-Smirnov (KS), o qual calcula se os dados coletados são ou não aderentes a uma Curva Normal ou de Gauss. O resultado do KS determinará o tipo de teste a ser aplicado posteriormente (WAGNER; MOTTA; DORNELLES, 2004).

A curva de Gauss mostra como se distribuem os dados em várias situações originadas de eventos mutuamente independentes (SPIEGEL, 1979). Os resultados para as 24 variáveis (itens da escala) apresentaram significância menor que $0,01(p<0,01)$ indicando que os dados não possuem uma distribuição normal, denotando que deve ser aplicado o teste de Mann-Whitney.

Após a análise preliminar e a constatação de que a distribuição normal não pode ser assumida, decidiuse pelos testes não paramétricos, que não assumem nenhuma distribuição teórica para os dados (SIEGEL, 1979). Com base na análise preliminar, usou-se o teste não paramétrico mais conhecido, Mann-Whitney, como alternativa ao teste $t$ de Student.

No teste estatístico evidenciado na Tabela 4, observa-se a significância com valores menores que $P<0,10$ para quatro assertivas, Armazenagem e movimentação de cargas, Custos e finanças, Gestão de pessoas e Gestão de contratos, e com valores maiores que $p>0,10$ para vinte. Sugere-se, então, a partir da lista dos conteúdos exigidos pelo mercado de trabalho, conforme o teste de Mann-Whitney com significância maior que $p>0,10$, que não há divergência entre as opiniões de professores e alunos respondentes, que acham que os conteúdos ensinados no curso são compatíveis estatisticamente com as exigências das empresas quando estão à procura de profissionais da área da Logística.

Quanto à divergência entre os conteúdos ensinados, são evidenciados que os Itens $4.7 / 5.7$ (Armazenagem e movimentação de cargas), 4.8/5.8 (Custos/Finanças), 4.11/5.11 (Gestão de pessoas) e 4.13 (Gestão de contratos), na opinião dos alunos respondentes, estão conectados com as exigências do mercado de trabalho; entretanto, os docentes entendem que estes conteúdos não atendem e, por isso, deveriam passar por uma avaliação, de modo que, na visão dos professores, atendesse às exigências do mercado de trabalho.

Assim, analisando os resultados da pesquisa realizada com os professores, alunos e coordenadores, é possivel dizer que existe, estatisticamente, uma diferença de opiniões nas intensidades dos escores apresentados em relação aos conteúdos aplicados sobre GCS nos CSTs em Logística oferecidos pelas IES pesquisadas na região metropolitana da Grande São Paulo. A Tabela 5 evidencia este resultado:

Tabela 5: Percepção dos respondentes versus ranking do mercado

\begin{tabular}{l|c|c|c|c}
\hline \multicolumn{1}{c|}{ Conteúdos exigidos pelo mercado de trabalho } & Mercado & Coordenador & Professor & Discentes \\
\hline Distribuição & $1^{\circ}$ & $3^{\circ}$ & $3^{\circ}$ & $5^{\circ}$ \\
\hline Indicadores de desempenho & $2^{\circ}$ & $23^{\circ}$ & $8^{\circ}$ & $13^{\circ}$ \\
\hline Gestão de estoques & $3^{\circ}$ & $10^{\circ}$ & $1^{0}$ & $2^{\circ}$ \\
\hline Planejamento, programação e controle da produção (PPCP) & $4^{\circ}$ & $1^{\circ}$ & $9^{\circ}$ & $6^{\circ}$ \\
\hline Gestão de transportes & $5^{\circ}$ & $12^{\circ}$ & $16^{\circ}$ & $3^{\circ}$ \\
\hline Gestão de compras & $6^{\circ}$ & $22^{\circ}$ & $12^{\circ}$ & $17^{0}$ \\
\hline Armazenagem e movimentação de cargas & $7^{\circ}$ & $5^{\circ}$ & $13^{\circ}$ & $1^{\circ}$ \\
\hline Custos/finanças & $8^{\circ}$ & $4^{\circ}$ & $14^{\circ}$ & $4^{\circ}$ \\
\hline Gestão de armazéns & $9^{\circ}$ & $13^{\circ}$ & $18^{\circ}$ & $7^{\circ}$ \\
\hline Supply Chain & $10^{\circ}$ & $2^{\circ}$ & $2^{\circ}$ & $8^{\circ}$ \\
\hline
\end{tabular}

Revista Alcance - Eletrônica - vol. 22 - n. 2 - abr.jun. 2015 


\begin{tabular}{|c|c|c|c|c|}
\hline Gestão de pessoas & $11^{0}$ & $11^{\circ}$ & $23^{\circ}$ & $9^{\circ}$ \\
\hline Gestão de operações & $12^{0}$ & $19^{\circ}$ & $10^{\circ}$ & $20^{\circ}$ \\
\hline Gestão de operadores logísticos & $13^{\circ}$ & $20^{\circ}$ & $15^{\circ}$ & $14^{\circ}$ \\
\hline Gestão de contratos & $14^{\circ}$ & $21^{\circ}$ & $24^{\circ}$ & $24^{\circ}$ \\
\hline Logística internacional & $15^{\circ}$ & $6^{0}$ & $22^{\circ}$ & $21^{\circ}$ \\
\hline Relacionamento com clientes & $16^{\circ}$ & $7^{0}$ & $19^{\circ}$ & $18^{\circ}$ \\
\hline Follow up de pedidos & $17^{\circ}$ & $24^{0}$ & $21^{\circ}$ & $23^{\circ}$ \\
\hline Canais de distribuição & $18^{\circ}$ & $8^{\circ}$ & $7^{0}$ & $10^{\circ}$ \\
\hline Sistemas/fluxo de informações & $19^{\circ}$ & $14^{\circ}$ & $6^{0}$ & $16^{\circ}$ \\
\hline Gerenciamento de projetos & $20^{\circ}$ & $15^{0}$ & $11^{\circ}$ & $19^{\circ}$ \\
\hline Planejamento estratégico & $21^{\circ}$ & $9^{\circ}$ & $4^{0}$ & $12^{\circ}$ \\
\hline Logística reversa & $22^{0}$ & $16^{0}$ & $20^{\circ}$ & $15^{\circ}$ \\
\hline Roteirização & $23^{\circ}$ & $17^{\circ}$ & $17^{\circ}$ & $22^{\circ}$ \\
\hline Gestão da qualidade & $24^{\circ}$ & $18^{\circ}$ & $5^{0}$ & $11^{\circ}$ \\
\hline
\end{tabular}

Fonte: Dados da pesquisa (2011).

Conclui-se, por meio dessa análise, que existe um descompasso entre a hierarquia dos conteúdos exigidos pelo mercado de trabalho e as percepções dos coordenadores, professores e discentes. Ao considerarse o ranking das exigências do mercado do $1^{\circ}$ ao $10^{\circ}$ lugar, há discrepâncias interessantes a serem analisadas:

1) O tema "Indicadores de Desempenho", que ocupa $02^{\circ}$ lugar no mercado, está em $23^{\circ}$ sob a ótica dos coordenadores e $13^{\circ}$ dos discentes, 0 que denota que o mercado está valorizando 0 assunto mais que as IES e os alunos;

2) Fato semelhante ocorre com o tema "Gestão de Compras", que ocupa o $6^{\circ}$ lugar no mercado, e $22^{\circ}$ pelos coordenadores; $12^{\circ}$ pelos professores e $17^{\circ}$ pelos alunos;

3) "Gestão de Transporte" ocupa a $5^{a}$ posição no mercado. Para os coordenadores e professores, este conteúdo aparece em $12^{\circ}$ e $16^{\circ}$ lugares respectivamente; destoando-se em relação às exigências do mercado;

4) Há temas que, na ótica dos cinco Coordenadores, estão sendo valorizados, tais como: "Logística internacional", "Relacionamento com clientes", "Canais de distribuição" e "Planejamento estratégico", que o mercado não está dando tanta ênfase;

5) Em relação a dois conteúdos que chamam a atenção, "Gestão de contratos" ocupa a 14a colocação; porém, coordenadores, docentes e discentes o avaliam na $21^{\circ}, 24^{\circ}$ e $24^{\circ}$, respectivamente e "Gestão da qualidade", em que o mercado de trabalho atribui uma baixa procura neste quesito, os docentes 0 colocam na $5^{\text {a }}$ posição, atribuindo uma grande importância na visão destes profissionais.

Nesta seção, foram analisados os resultados encontrados na survey realizada com coordenadores, docentes e discentes dos CSTs em Logística na Grande São Paulo.

\section{CONSIDERAÇÕES FINAIS E RECOMENDAÇÕES}

Este trabalho procurou contribuir com o Ensino de Logística e Gestão de Cadeias de Suprimentos nos Cursos Superiores de Tecnologia (CST) em Logística, oferecidos pelas IES da Grande São Paulo, confrontando a visão de coordenadores, professores e discentes sobre os conteúdos ensinados e o que o mercado de trabalho exige dos egressos. A pesquisa documental permitiu constatar que, de acordo com o INEP (2010), na última década, houve um crescimento expressivo no número de IES, que passaram a oferecer os Cursos Superiores de Tecnologias. 
Constatou-se que, em função do atual contexto econômico nacional e internacional e das pressões exercidas pela globalização, o aumento na oferta dessa modalidade de ensino de graduação pelas IES está vinculado às reformas ocorridas no sistema educacional a partir da LDBN no 9.394/96 e o Decreto Federal $n^{\circ}$ 2.208/97. Em um âmbito maior, pode-se inferir que o aumento na oferta desta modalidade de ensino deve-se também às configurações socioeconômicas e políticas do país, que buscam alinhar suas estratégias educacionais neste contexto.

Tal crescimento acelerado desses Cursos Superiores de Tecnologia, afirmado por Basílio (2005), também foi observado nos CSTs em Logística. Esta evolução leva a algumas reflexões sobre os possíveis impactos que este tipo de curso, tão necessário no atual cenário econômico no Brasil e no mundo, traz para o mercado de trabalho, para as IES, professores e discentes.

Durante o desenvolvimento deste estudo, por meio de pesquisa documental nos sites de recolocações de três renomadas empresas, foi constatado em 60 anúncios oferecidos que a procura por profissionais de Logística corrobora as constatações do trabalho de Bowersox, Closs e Cooper (2007), apontando no sentido de que as organizações requerem um perfil de conhecimentos técnicos que abrange: Planejamento, aquisição, recebimento, armazenagem, distribuição e transporte de matérias-primas e produtos acabados, corroborando com o perfil de competências esperadas ao profissional de Tecnologia em Logística pelo Catálogo Nacional de Cursos Superiores de Tecnologia instituído do MEC (2010).

Dentro das ofertas de emprego destinadas ao profissional de Logística, de acordo com a pesquisa nos sites de recolocação, constatou-se que $71,84 \%$ dos conhecimentos técnicos exigidos, relativos a dez conteúdos, são requeridos: indicadores de desempenho, distribuição, gestão de estoques, PPCP, gestão de transportes, gestão de compras, armazenagem e movimentação de cargas, custos e finanças, gestão de armazéns e conhecimentos gerais de supply chain.

0 mercado de trabalho exige um profissional apto a realizar suas atribuições em um ambiente de negócios globalizados, e cabe às IES preparar este profissional. Com esta visão, esta pesquisa procurou conhecer, na percepção de coordenadores, professores e discentes, a intensidade dos conteúdos ensinados pelas IES e responder se estes correspondem às necessidades do mercado de trabalho. Considerada a limitação da pesquisa, entende-se que a questão de pesquisa foi respondida.

A pesquisa foi limitada à região metropolitana da Grande São Paulo, em função do elevado número de IES e de empresas nacionais e estrangeiras existentes na região, as quais demandam por mão de obra especializada em funções logísticas e conhecimentos de Gestão de Cadeias de Suprimentos. Foi detectada na pesquisa a existência de 41 IES que oferecem o CST em Logística, situadas na Grande São Paulo; entretanto, apenas quatro concordaram em participar, o que caracterizou ser uma amostra intencional e por conveniência, em função da acessibilidade das informações por parte das IES. Diante disso, é preciso reiterar a limitação da pesquisa, cujos resultados ficam adstritos às quatro IES que aceitaram participar, por intermédio dos coordenadores, professores e discentes do curso.

$\mathrm{Na}$ visão dos cinco coordenadores pesquisados, os conteúdos ensinados estão sintonizados com as necessidades do mercado de trabalho. Para os professores, a mediana da intensidade de dez conteúdos aponta para valores iguais ou inferiores a 6,0 , o que, para eles, os conteúdos devem ser revistos para atender às necessidades do mercado de trabalho; entretanto os outros catorze conteúdos estão dentro das necessidades.

Constatou-se que, no quadro de pessoal das IES, $30 \%$ dos 68 docentes pesquisados são mestres ou doutores, atendendo às exigências do MEC. Apesar de 26,32\% não exercem atividades fora da área acadêmica, pode-se inferir que os demais contribuem de alguma forma com o alinhamento entre a teoria e a prática, explorando significativamente para que o saber tácito dos professores e dos alunos seja valorizado na sala de aula. Os 212 discentes pesquisados consideram que os conteúdos oferecidos estão sintonizados com as necessidades do mercado de trabalho e que tais conteúdos estariam preparando-os para o mercado de trabalho, facilitando dessa forma sua empregabilidade na área da Logística.

Conclui-se que existem quatro conteúdos que divergem quanto a opiniões de professores e alunos: Armazenagem e Movimentação de Cargas, Custos/Finanças, Gestão de Pessoas e Gestão de Contratos, sendo que os vinte restantes convergem com os requisitos demandados pelo mercado de trabalho. Percebeu-se, porém, que todos os conteúdos demandados são apresentados aos discentes e alinham-se às necessidades do mercado, independentemente dos escores atribuídos a eles. 
A contribuição deste estudo está na divulgação da realidade apresentada, a qual pode ser inserida na agenda de debates sobre ensino e pesquisa em Logística e Gestão da Cadeia de Suprimentos nos Cursos Superiores de Tecnologia em Logística. Isso permite acompanhar os impactos da expansão desses cursos para as IES, para os docentes e para os alunos. De forma mais ampla, também podem influenciar no desenvolvimento de políticas públicas voltadas para essa área, uma vez que estas necessitam de contínuo acompanhamento e adequação. Outra contribuição está na reflexão de professores e pesquisadores sobre a relevância de suas atividades, ao menos no que tange à aplicação direta dos conceitos que estudam e ensinam na prática empresarial.

Os resultados obtidos recomendam a realização de novas pesquisas, que poderão explorar os questionamentos levantados em outras localidades brasileiras, comparando as necessidades do mundo do trabalho e os currículos e as práticas pedagógicas dos cursos de Tecnologia em Logística em outros Estados brasileiros ou em outros cursos. Outra recomendação para trabalhos futuros é a ampliação da amostra para outras regiões e/ou maior quantidade de IES, o que poderá, inclusive, requerer outras formas para o tratamento estatístico dos dados a serem coletados.

Finalmente, espera-se que a pesquisa realizada tenha oferecido um diagnóstico sobre a oferta dos conteúdos sobre Gestão da Cadeia de Suprimentos nos cursos de Graduação Superior de Tecnologia em Logística da Grande São Paulo. Estes resultados poderão ser usados para promover a aproximação das condições de oferta de tais conteúdos com as recomendações emanadas das Diretrizes Curriculares Nacionais.

\section{REFERÊNCIAS}

BABBIE, E. Métodos de pesquisas de Survey. Belo Horizonte: Ed. UFMG, 1999.

BALLOU, R.H. The evolution and future of logistics \& supply chain management. European Business Review, v. 19, n. 4, p. 332-348, 2007.

BASíLIO, M. D. A implantação de cursos superiores de tecnologia em São Paulo: um estudo exploratório. Dissertação (Mestrado em Administração de Empresas) - Centro Universitário Álvares Penteado - UNIFECAP. São Paulo, 2005.

BAYLEY, T.; BADWAY, N.; GUMPORT,P.J. For-Profit higher education and community colleges. Disponível em <http://www.stanford.edu/group/ncpi/documents/pdfs/forprofitandcc.pdf>. Acesso em: 13 Setembro 2011.

BOWERSOX, D.J.; CLOSS, D.J.; COOPER, M. B. Supply Chain Logistics Management. 2. ed. McGraw-Hill, New York, NY, 2007.

BRASIL. Lei n. 9.394/96, de 20 de dezembro de 1996 Estabelece as diretrizes e bases da educação nacional.

CATHO. Empregos. Disponivel em: <http:://www.catho.com.br>. Acesso em: 02 Fevereiro 2011.

CHRISTOPHER, M. Logística e gerenciamento da cadeia de suprimentos. São Paulo: Pioneira, 1999.

CNE - CONSELHO NACIONAL DE EDUCAÇÃO. Parecer CNE/CES 436, de 2 de abril de 2001. Cursos Superiores de Tecnologia - formação de tecnólogos. Diário oficial, Brasil, DF, Seção 1 E, p.67, 6 abril 2001.

COOPER, D. R.; SCHINDLER, P. S. Métodos de Pesquisa em Administração. Trad. Luciana de Oliveira da Rocha. 7. ed. Porto Alegre: Bookman, 2003.

CORDÃO, F.A. Parecer CNE/CES no 436/01. Diretrizes Curriculares Nacionais para a Educação Profissional de Nível Tecnológico. Disponível em: <www.sinepe-mg.org.br/downloads_restrito.php>. Acesso em: 15 abr. 2011.

COX, A; SANDERSON, J.; WATSON, G. Supply chains and power regimes: Toward an analytic framework for managing extended network of buyer and supplier relationships. Journal of Supply Chain Management, v.37, n.2, p.28-35, 2001.

CZINKOTA, M. R. et al. Marketing: as melhores práticas. São Paulo: Bookman, 2001.

FIGUEIREDO, K.; ARKADER, R. As mudanças no ambiente empresarial e o ensino da logística no Brasil.

Revista Latinoamericana de Administración, v. 22, p 13-27, 1999. 
GAMMELGAARD, B.; LARSON, P.D. Logistics skills and competencies for supply chain management. Journal of Business Logistics, v. 22, n. 2, p. 27-49, 2001.

GANGA, G. M. D.; SANTOS, F. C. A.; MUSSETTI, M. A. Proposta de criação de um curso de graduação em logística. Anais... IN: XXIII Encontro Nacional de Engenharia de Produção - ENEGEP. Ouro Preto, 2003.

GEORGES, M. R. R.; SEYDELL, M.R.R. Dificuldades no ensino da logística. Anais... IN: V Congresso Virtual Brasileiro de Administração - CONVIBRA. São Paulo, 2008.

GIL, A. C. Como elaborar um projeto de pesquisa. $5^{a}$ Ed. São Paulo: Atlas, 2010.

GUIMARÃES, A. A. A concepção e o modelo de universidade dos cursos superiores de tecnologia do Centro Federal de Educação Tecnológica do Paraná: o caso da unidade de Ponta Grossa. Dissertação (Mestrado em Tecnologia) Programa de Pós-Graduação em Tecnologia. Centro Federal de Educação Tecnológica do Paraná. Curitiba, 2001.

HABIB, M.; JUNGTHIRAPANICH, C. An Empirical Study of Educational Supply Chain Management for the Universities. Proceedings... IN: International Conference on Industrial Engineering and Operations Management Dhaka, Bangladesh, January $9-10,2010$.

HOLWEG, M.; DISNEY, S.; HOLMSTROM, J.; SMOROS, J. Supply Chain Collaboration: Making Sense of the Strategy Continuum. European Management Journal, v. 23, n.2, pp. 170-181, 2005.

INEP - INSTITUTO NACIONAL DE ESTUDOS E PESQUISAS EDUCACIONAIS. Sinopses estatísticas da educação superior. Disponível em: <http://www.inep.gov.br/superior/sinopse/default.asp> Acesso em: 18 Janeiro 2011.

LANCIONI, R.; FORMAN, H.; SMITH, M. F. Logistics and supply chain education: Roadblocks and challenges. International Journal of Physical Distribution \& Logistics Management, v. 31, n. 10, p. 733 - 745, 2001.

LIMA FILHO, D. L. Universidade tecnológica e redefinição da institucionalidade da educação profissional: concepção e práticas em disputa. In: MOLL, J. e colaboradores. Educação profissional e tecnológica no Brasil contemporâneo: desafios, tensões e possibilidades. Porto Alegre: Artmed, 2010.

MALHOTRA, N. Pesquisa de marketing: uma orientação aplicada. Porto Alegre: Bookman, 2006.

MANAGER. Empregos. Disponível em: <http:://www.manager.com.br> Acesso em: 02 Fevereiro 2011.

MATSUKUMA, C. M. O; HERNANDEZ, J. M. C. Escala e métodos de análise em pesquisa de satisfação de clientes. Revista de Negócios, Blumenau, v. 11, n.1, p. 48-65. janeiro/março 2006.

MEC - Ministério da Educação e Cultura. Politicas públicas para a educação profissional e tecnológica. Brasília, 2004.

MICHAEL PAGE. Ofertas de Empregos. Disponível em: <http:://www.michaelpage.com.br>. Acesso em: 03 Fevereiro 2011.

MYERS, M. B.; GRIFFITH, D.A.; DAUGHERTY, P. J.; LUSCH, R.F. Maximizing the human capital equation in Logistics: Education, Experience and skills. Journal of Business Logistics. v. 25, n. 1, p. 211-232, 2004.

MOURA, D. H. Algumas implicações da reforma da educação superior sobre a educação profissional e tecnológica: Il. Holos, Ano 21, dezembro 2005.

MURPHY, P.R.; POIST, R.F. Skill requirements of skill requirements of senior-level logisticians: a longitudinal assessment. Supply Chain Management,v.. 12, n. 6, p. 423-32, 2007.

RADOVILSKY, Z;; HEGDE; V. Trends in Supply Chain Management Job Requirements: a Logitudial study. Journal of Supply Chain and Operations Management, v. 10, n. 1, p. 168-181, 2012.

RAZZAQUE, M.A.; SIRAT, M.S.B. Skill requirements: perceptions of the senior Asian logisticians. International Journal of Physical Distribution \& Logistics Management,v.. 31, n. 5, p. 374-95, 2001.

RICHARDSON, R. J. Pesquisa social: métodos e técnicas. 3. ed. São Paulo: Atlas, 2007.

SIEGEL, S. Estatística não paramétrica para as ciências do comportamento. Tradução de Alfredo Alves de Farias. São Paulo: McGraw-Hill, 1979. 
SODHI, M.S.; SON, B.G.; TANG, C.S. ASP, The Art and Science of Practice: What Employers Demand from Applicants for MBA-Level Supply Chain Jobs and the Coverage of Supply Chain Topics in MBA Courses. Interfaces, v. 38, n.6, p. 469-484, 2008.

SPIEGEL, M. R. Estatística. 12. ed. São Paulo: Mcgraw-hill, 1978.

STOREY, J. et al. Supply chain management: Theory, practice and future challenges. International Journal of Operations \& Production Management, v. 26, n.7, p 754-774, 2006.

TAKAHASHI, A. R. W. Cursos superiores de tecnologia em gestão: reflexões e implicações da expansão de uma (nova) modalidade de ensino superior em administração no Brasil. Revista de Administração Pública, v. 44, n.2, p. 385-414, 2010.

TAKAHASHI, A. R. W. Descortinando os processos de aprendizagem organizacional no desenvolvimento de competências em instituições de ensino. Tese (Doutorado em Administração) - Faculdade de Economia, administração e Contabilidade, Universidade de São Paulo. São Paulo, 2005.

THAI, V.V.; CAHOON, S.; TRAN, H.T. Skill requirements for logistics professionals: findings and implications. Asian Pacific Journal of Marketing and Logistics, v. 23, n. 4, p. 553-574, 2011.

WAGNER, M. B.; MOTTA, V. T.; DORNELLES, C. SPSS passo a passo: statistical package for the social sciences. Caxias do Sul: Educs, 2004.

VAN HOEK, R.I. Logistics Education: Achieving Market and research driven skill development. International Journal of Physical Distribution \& Logistics Management. v. 31, n. 7, p. 505-519, 2001. 